\title{
К ВОПРОСУ ОБ ИЗМЕНЕНИИ РОЛИ ПРАВА В ОБЕСПЕЧЕНИИ ПОТРЕБНОСТЕЙ ЧЕЛОВЕКА В УСЛОВИЯХ АВТОМАТИЗАЦИИ ПРОИЗВОДСТВА
}

\section{ON THE ISSUE OF CHANGING THE ROLE OF LAW IN ENSURING HUMAN NEEDS IN THE CONDITIONS OF PRODUCTION AUTOMATION}

I. Krizhus

Summary. The presented research is devoted to the question of the further development of law through the Marxist vision of the laws of the development of society. A large place in the work is occupied by the consideration of the concept of social equality and the means of achieving it. The article shows the forecast of the development of industrial relations and law in the next 20 years based on the data of consulting companies. In conclusion, the author concludes that the Marxist theory rightly anticipated the genesis of the basis and superstructure of human society. The article may be of interest to legal scholars and specialists dealing with current problems of genesis of law.

Keywords: marxism, capitalism, socialism, communism, revolution, jurisprudence, law, right, equality, universal basic income, automation, artificial intelligence.
$\mathbf{K}$ ак известно, одна из функций науки - прогностическая. Спрогнозировать дальнейшее развитие права позволяет именно материалистическое учение, основанное на диалектике Гегеля.

Одной из основных положительных черт материалистической концепции права является обнаружение зависимости права от социально-экономических факторов, которые оказывают наиболее значительное влияние на него.

Причиной и движущей силой исторического развития являются внутренние противоречия в производственной сфере, которые с развитием общества приобретают форму классовой борьбы. По мнению Маркса, эта причина объективна.

Марксистско-ленинская теория в структуре общества выделяет экономический базис, политическую и юридическую надстройку. Экономический базис это совокупность производственных отношений между

\author{
Крижус Игорь Константинович \\ Старший преподаватель, Сибирский федеральный \\ университет \\ kryzius@yandex.ru
}

Аннотация. Представленное исследование посвящено вопросу дальнейшего развития права через марксистское видение закономерностей развития общества. Большое место в работе занимает рассмотрение понятия социального равенства и средств его достижения. В статье на основе данных консалтинговых компаний показан прогноз развития производственных отношений и права в ближайшие 20 лет. В заключении статьи автор приходит к выводу, что марксистская теория справедливо предвосхитила генезис базиса и надстройки человеческого общества. Статья может представлять интерес для ученых юристов и специалистов, занимающихся актуальными проблемами правогенеза.

Ключевые слова: марксизм, капитализм, социализм, коммунизм, революция, юриспруденция, право, закон, равенство, безусловный основной доход, автоматизация, искусственный интеллект. людьми, обусловленных определенным уровнем развития материальных производительных сил общества и определяющих его структуру.

Право является частью надстройки. Как писал советский классик в области юриспруденции Алексеев С.С.: «Как и государство, право наиболее близко расположено к экономическому базису - непосредственней и быстрей, чем другие надстройки, выражает его требования» [6, с. 392]. Развитие права детерминировано развитием экономического базиса. Так по его же мнению: «...сам факт существования права, его содержание и развитие заданы, обусловлены объективными требованиями экономического базиса» [6, с. 235].

В соответствии с материалистической диалектикой самого Маркса, производственные отношения определяются уровнем развития производительных сил. На основании этого Маркс предложил свою теорию периодизации истории, утверждая, что развитие человеческого общества проходит через пять «обще- 
ственно-экономических формаций». Соответственно уровень развития права тоже будет зависеть от уровня развития производительных сил.

Наиболее близкие для нас общественно-экономические формации это: капиталистическая и коммунистическая, в первой мы проживаем в настоящее время, последняя - является предвосхищаемой, будущей.

Термин коммунизм (от лат. commūnis «общий») — гипотетический общественный и экономический строй, основанный на полном равенстве, общественной собственности на средства производства [9, с. 152]. На практике такого строя никогда не существовало, однако термин «коммунистическое государство» применялся западной прессой к СССР и странам, объявившим себя или считавшимися социалистическими. Интересен тот факт, что: «Изначально понятие «капитализм» активно использовалось в социалистической литературе как антоним социализма и носило негативные коннотации» [4].

В противоположность коммунизму, капитализм это экономическая система производства и распределения, основанная на частной собственности, юридическом равенстве и свободе предпринимательства [9, с. 152]. При сравнении двух этих понятий заметно, что свойством первого является фактическое (экономическое) равенство, а свойством второго - юридическое равенство. Как можно усмотреть, роль права и там и там заключается в обеспечении равенства, вопрос лишь в том, достигается ли оно формально или фактически.

Советский и российский историк и юрист Сонин В.В. в работе «Всеобщая история права» пишет: «Не случайно среди принципов буржуазного права важнейшее место было отведено равенству. Одним из основных условий функционирования капиталистической системы хозяйства является юридическое равенство всех участников общественных отношений» [10, с. 45]. По его убеждению: «Сам процесс становления буржуазных систем права протекал медленнее и был значительно более длинным, чем процесс утверждения буржуазии у власти и создания новой государственности» $[10$, с. 45].

Марченко М.Н. в одной из своих работ также пишет о формальном равенстве, связывая его именно с капитализмом: «С приходом на историческую арену капитализма в странах Западной Европы, Северной Америки и в ряде других стран установилось и законодательно закрепилось формально-юридическое равенство. Но вместе с тем не только сохранилось, а ещё больше углубилось и расширилось по мере развития данной общественно-экономической формации, характеризующейся накоплением несметных материальных богатств у одной, незначительной части общества и обнищанием всего остального общества, фактическое неравенство» [7, с. 430].

Как справедливо подметил в своем труде Сырых В.М.: «Действительно, в современном гражданском обществе, которое еще не способно в полной мере обеспечить производство материальных и духовных благ в мере, способной удовлетворить потребности всех его членов, равенство, закрепляемое правом, может быть по преимуществу только формальным» [11, с. 447]. По его мнению: «Положения классиков диалектического материализма о формальном праве в условиях буржуазного общества, сформулированные применительно к условиям XIX и начала XX в., в настоящее время надлежит скорректировать с учетом современного состояния экономики развитых капиталистических стран, а также норм и принципов международного и внутринационального права, которыми каждое государство обязывается обеспечивать минимальный стандарт материальных и духовных благ каждому, независимо от его пола, расы, национальности, уровня благосостояния и других обстоятельств» [11, с. 448].

Закономерно, что достичь фактического равенства, для снятия противоречий капиталистической организации общества, позволяют, прежде всего, экономические средства, а не только правовые. В 1795 году англичанином Томасом Пейном впервые была предложена идея безусловного дохода в качестве инструмента борьбы с бедностью. В настоящее время идея безусловного обеспечения потребностей каждого человека кажется достаточно утопичной и неизбежно связана с идеями об идеальном обществе, социализме, отсутствием социальной стратификации.

Однако, во многих странах мира уже проводили отдельные эксперименты с базовым доходом - например, в Бразилии, Голландии, Намибии, Канаде, Кении и Уганде. Исследования показали, что опасения в духе «безработные все потратят на выпивку» не оправдываются. Эксперименты в целом показывали положительные эффекты базового дохода, но в масштабах целой страны никто пока не экспериментировал [4]. Последний подобный эксперимент проводился в Финляндии, где каждому гражданину предложено было выдавать по 800 евро.

Конечно, идея безусловного основного дохода прошла долгий путь от философской концепции до гарантированного права человека в постиндустриальную эпоху. На протяжении истории в пользу такого дохода успели высказаться приверженцы большинства поли- 
Automation impact will be global under multiple modeled scenarios

$\%$ of work hours automated

0

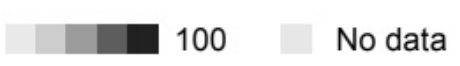

2036

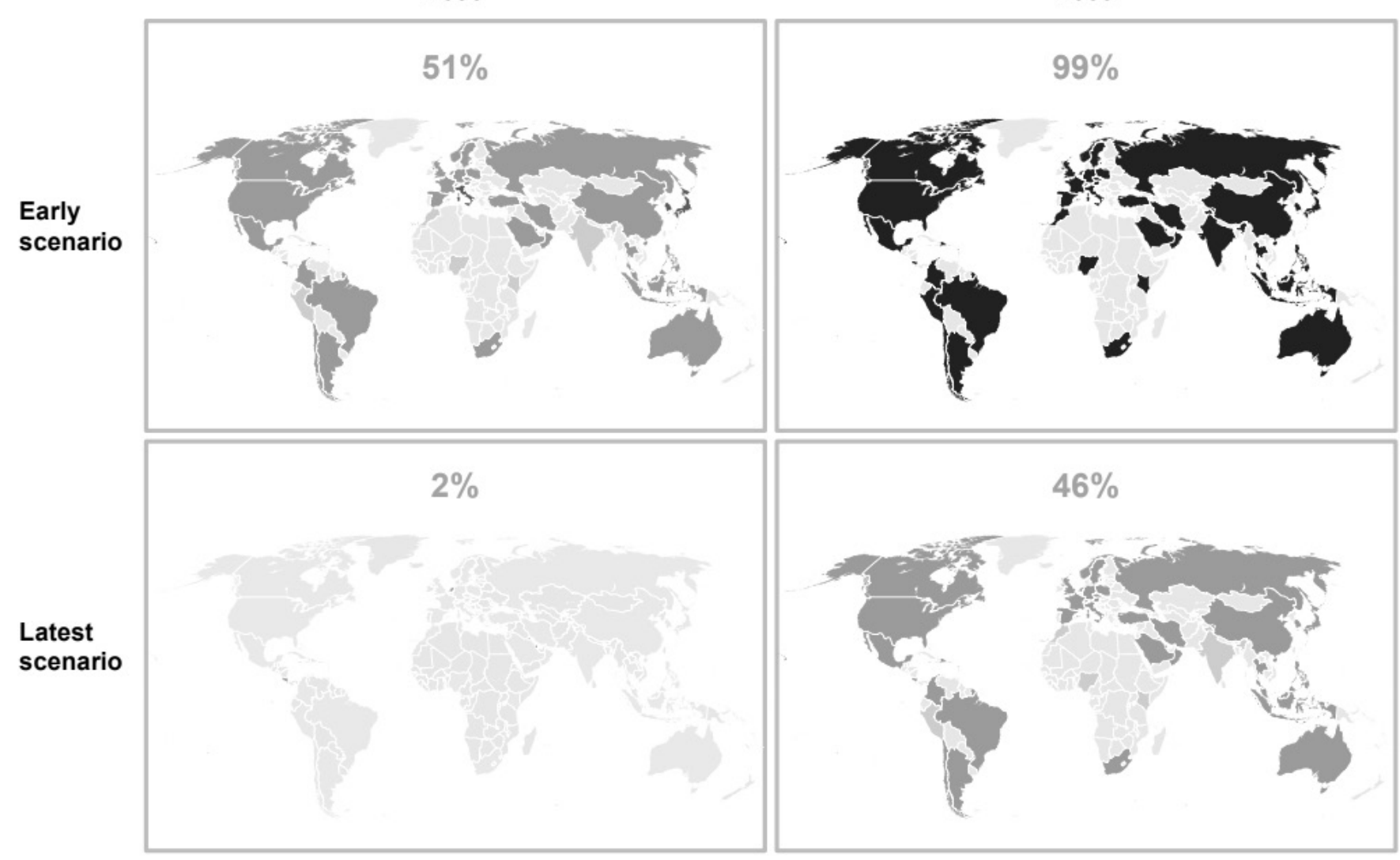

SOURCE: US Bureau of Labor Statistics, 2014 O*Net database; McKinsey Global Institute analysis

Рис. 1.

тических взглядов, сейчас его поддерживают как правые, так и левые.

В 2010-е годы концепцию безусловного основного дохода стали воспринимать как средство для «смягчения углов капитализма», а также как попытку реформировать устаревшие механизмы «государства всеобщего благосостояния». Однако главным стимулом для возвращения темы базового дохода в повестку дня стала именно автоматизация. В статистике поисковых запросов Google за последние 5 лет можно отследить едва заметную корреляцию: как только начинает расти популярность запроса «автоматизация», впервые за долгие годы проявляется интерес к безусловному основному доходу [3].

По мнению аналитиков консалтинговой компании McKinsey \& Со автоматизация будет глобальной силой, которая затронет все страны, независимо от того, име- ют ли они передовую или иную экономику. На рисунке 1 представлено влияние автоматизации, которое будет глобальным в условиях множественных смоделированных сценариев [1].

Новый отчёт компании McKinsey \& Со прогнозирует, что к 2030 году без работы в мире останется 800 млн. человек, то есть примерно пятая часть всей рабочей силы. К таким выводам аналитики пришли после того, как проанализировали данные о 800 профессиях в 46 странах [5].

Ведущие мыслители в прошлом, от Дэвида Рикардо до Карла Маркса и Джона Мейнарда Кейнса, вызывали озабоченность по поводу влияния технологических изменений на занятость.

На фоне быстрых успехов в робототехнике и работе по созданию искусственного интеллекта, ряд уче- 
ных и технологов современности утверждают, что повсеместная автоматизации, включая искусственный интеллект, может стать особенно разрушительной для современного рынка рабочей силы, а соответственно скажется на системе производственных сил в обществе, т.е. на том самый экономический базис.

Политический экономист Дэвид Рикардо ещё в начале 19 века был обеспокоен тем, что машины излишни, Карл Маркс в 1850-х годах предвидел эру, когда средства производства будут преобразованы «автоматической системой машин». Стоит только удивляться подобной прозорливости этих умов. В 1930 году Джон Мейнард Кейнс придумал термин «технологическая безработица», чтобы описать ситуацию, в которой инновации, которые уменьшали использование труда, опережали темпы создания новых рабочих мест» [2].

Мы являемся очевидцами событий, когда происходит трансформация производительных сил, соответственно, меняется весь экономический базис современных капиталистических обществ. Поэтому именно сейчас встаёт вопрос об обеспечении минимального объёма материальных и духовных благ для лиц, чья компетенция не позволит им быть занятыми в производстве.

Закономерно, что для снятия противоречий капиталистической организации общества, для достижения фактического равенства людей в обществе, или хотя бы приближения к нему, целесообразно оперировать не только экономическими средствами, но и правом, входящим в надстройку.

Право объективно будет претерпевать изменение в связи с изменяющимся базисом. Вопрос в том, каким оно будет, какова будет роль права в новых экономических условиях при всевозрастающей автоматизации, в условиях новой революцию в развитии средств производства. Не приведёт ли это, исходя из положений материалистического учения, к смене общественно-экономической формации?

По мнению теоретиков марксизма-ленинизма, главной причиной смены формаций является классовая борьба, в основе которой лежат количественные изменения экономического базиса, которые в определённый момент переходит в новое качество, в новую формацию. Произойдёт ли это планомерно или посредством очередной революции будет зависеть и от того, как право будет обеспечивать равенство между людьми в новых условиях автоматизации, когда доля незанятых будет несравненно больше, доли людей, занятых в экономике.

Всё это может стать причиной социальных потрясений в будущем, когда большинство населения не сможет продать то единственное, что у них есть свой труд, ибо он более не станет нужен новому технологическому обществу.

Будет ли тогда обеспечиваться порядок в обществе, основанном на формальном равенстве, т.е. капиталистическом обществе. Формально у каждого человека, который останется за бортом занятости будет возможность попасть в небольшой по численности класс собственников средств производства, либо прослойку людей занятых на обслуживании машин, но реализовать своё право на труд смогут немногие. Поэтому право в уже недалёком будущем неизбежно должно будет обеспечивать не только формальное равенство, но и стремиться обеспечить фактическое, чтобы избежать социальных потрясений и обеспечить баланс интересов всех классов общества либо построение новой модели бесклассового общества.

\section{ЛИТЕРАТУРА}

1. A future that works: automation, employment, and productivity January 2017 - Режим доступа: https://www.mckinsey.com/ /media/McKinsey/ Global\%20Themes/Digital\%20Disruption/Harnessing\%20automation\%20for\%20a\%20future\%20that\%20works/MGl-A-future-that-works-Full-report.ashx (дата обращения: 29.05.2018).

2. David Ricardo, On the principles of political economy and taxation, 1817; Karl Marx, Grundrisse: Foundations of the critique of political economy, 1858; John Maynard Keynes, «Economic possibilities for our grandchildren» in Essays in Persuasion, Macmillan 1933.

3. Красильникова Ю. Идея просто так раздавать деньги нравится уже почти всем — Режим доступа: https://hightech.fm/2018/01/07/ubi_2018 (Дата обращения: 29.05.2018).

4. В Финляндии каждому гражданину планируют ежемесячно выплачивать просто так по 800 евро — Режим доступа: https://ru.tsn.ua/groshi/ v-finlyandii-kazhdomu-grazhdaninu-planiruyut-ezhemesyachno-vyplachivat-prosto-tak-po-800-evro-520264.html (Дата обращения: 29.05.2018).

5. Jobs lost, jobs gained: workforce transitions in a time of automation December - Режим доступа: https://www.mckinsey.com/ /media/Mckinsey/ Industries/Public\%20and\%20Social\%20Sector/0ur\%20Insights/What\%20the\%20future\%20of\%20work\%20will\%20mean\%20for\%20jobs\%20skills\%20 and\%20wages/MGl-Jobs-Lost-Jobs-Gained-Executive-summary-December-6-2017.pdf (Дата обращения: 29.05.2018).

6. Алексеев С.С. Проблемы теории государства и права: Учебник/ Под ред. С.С. Алексеева.— М.: Юрид. Лит., 1979. — 392 с. 
7. Марченко М.Н. Правовое государство и гражданское общество (теоретико-правовое исследование): учебное пособие / М.Н. Марченко.- Учеб. изд.- - М.: Проспект, 2015.- 648 с.

8. Наумова Е.И. История понятия «капитализм»: от политического лозунга к научному термину // Международный журнал исследований культуры. № 1(18), 2015. С. 108-115.

9. Райзберг Б.А., Лозовский Л.Ш. Коммунизм // Словарь современных экономических терминов,- М.: Айрис-пресс, 2008. - 480 с.

10. Сонин В.В. Всеобщая история права: Учеб. пособие. 4 е изд., испр. / В.В. Сонин - Владивосток: Изд-во ВГУЭС, 2006. - 104 с.

11. Сырых В.М. Материалистическая теория права: Избранное /В.М. Сырых — М.: РАП, 2011. — 1259 с.

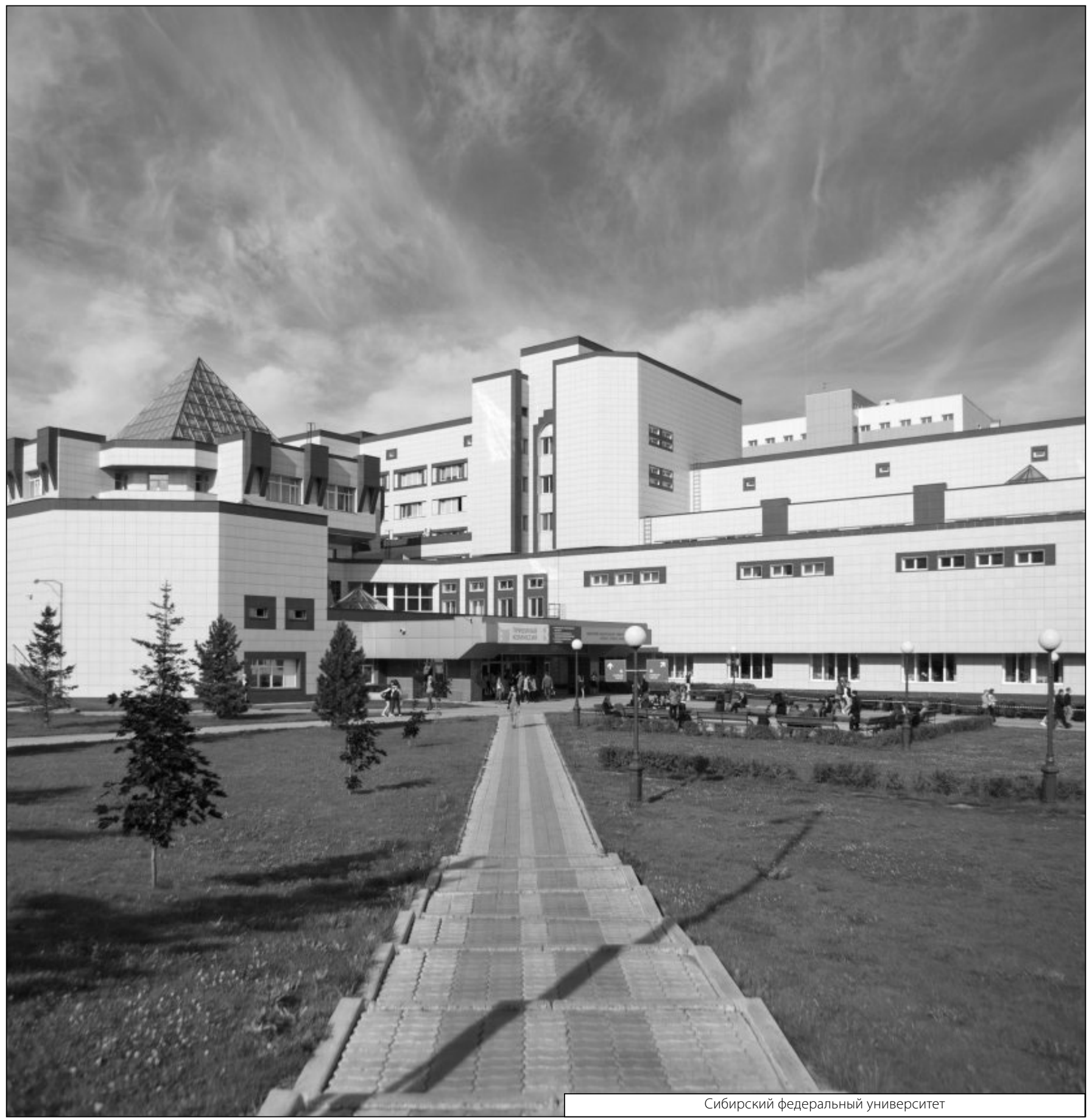

